\title{
Review of Marketing Science
}

Volume 2

2004

Article 4

\section{Product Entry Timing in Dual Distribution Channels: The Case of the Movie Industry}

\author{
Ashutosh Prasad* \\ Bart Bronnenberg ${ }^{\dagger}$ \\ Vijay Mahajan
}

*The University of Texas at Dallas, aprasad@utdallas.edu

$\dagger$ The University of California, Los Angeles, bart.bronnenberg@anderson.ucla.edu

†UT Austin, vijay.mahajan@mccombs.utexas.edu

Copyright (c)2004the authors. All rights reserved. No part of this publication may be reproduced, stored in a retrieval system, or transmitted, in any form or by any means, electronic, mechanical, photocopying, recording, or otherwise, without the prior written permission of the publisher, bepress, which has been given certain exclusive rights by the author. Review of Marketing Science is produced by The Berkeley Electronic Press (bepress). http://www.bepress.com/romsjournal 


\title{
Product Entry Timing in Dual Distribution Channels: The Case of the Movie Industry*
}

\author{
Ashutosh Prasad, Bart Bronnenberg, and Vijay Mahajan
}

\begin{abstract}
In many durable goods industries, firms continuously offer new products to customers and market them in different versions through different channel of distribution. This paper examines the issue of when to introduce the product into the different channels. The determinants of entry time include the discounting of future profits, the foresight of the firm, customers' expectations, and the possibility of cannibalization. Of special interest is the effect of customers' expectations about the timing of sequential entries. Specifically, it is shown here that profits decline if firms ignore the role of customer expectations. We discuss how our results can be used to get insights into the workings of the US motion picture industry, which is characterized by sequential introduction of movies first into theaters followed by home video. Finally, a closed form solution for an optimal sequential timing policy is provided.
\end{abstract}

KEYWORDS: New Product Introductions, Durable Goods, Motion Picture Industry

\footnotetext{
*Ashutosh Prasad is Assistant Professor of Marketing at The University of Texas at Dallas. Bart Bronnenberg is Associate Professor of Marketing at the John E. Anderson Graduate School of Management, The University of California at Los Angeles. Vijay Mahajan is the Dean of the Indian School of Business at Hyderabad India. He also holds the John P. Harbin Centennial Chair in Business in the McCombs School of Business, The University of Texas at Austin. The authors thank Sridhar Balasubramanian, Rick Briesch and Preston McAfee for their many helpful suggestions. The paper has benefited from the comments of seminar participants at the University of Central Florida, the University of Georgia at Athens, the University of Nebraska, Lincoln, the University of Texas at Dallas and Babson College.
} 


\section{INTRODUCTION}

It is frequently observed that when firms introduce products to the market in multiple versions, they follow a pattern of introducing the high-margin version first, followed, after a delay, by the low-margin version. Several examples of such a pattern may be cited. Six months after the theatrical release of a movie, it is re-released on videos for home consumption (Childs 1992). Paperback versions of books are released after about a year of their hardback release (Wilson and Norton 1989). High quality cars, computers and cameras are introduced before their corresponding lower quality versions. And fashion houses, such as Armani, introduce designs sequentially into lower price outlets after every fashion season (Pesendorfer 1995).

In all these examples, there are no developmental constraints preventing the release of both versions simultaneously, but the firm chooses to introduce the high-margin version first. An obvious motivation for this choice is that introduction strategies can influence profits substantially. Since the versions are substitutes, the advantage of sequential introduction is that there is less cannibalization of the high-margin version by the low-margin one. The disadvantage is that firms have to discount their earnings from the low-margin version to a greater extent. It would appear that this advantage and disadvantage can be traded off to obtain an optimal entry time for the low margin version, and much of the product introduction timing literature in marketing has followed this approach (e.g. Mahajan and Muller 1996, Norton and Bass 1987, Wilson and Norton 1989). However, in many industries, including those cited above, cannibalization is not the only determinant of introduction time.

An interesting feature in these industries is the repeated nature of the problem. For example, a publisher faces the paperback timing decision with every new book, and movie distributors with every new movie. In such cases, sequential entry decisions are likely to influence customers' expectations about sequential entry in the future. Customers act on the expectations they form about future introduction times based on the firm's past behavior. Only after taking this into consideration can the firm properly maximize profits with its choice of introduction times. The goal of this paper is to study the role of expectations in entry decisions and, thereby, the optimal introduction strategy for the product.

This paper shows that by ignoring customer expectations, the existing theoretical literature prescribes a less profitable outcome for the firm, and over time results in the two versions of each product being introduced closer and closer to each other until, finally, they are introduced simultaneously. A better outcome is achieved by taking customer expectations into consideration. But, even then, it will be seen that achieving the best outcome depends on the sequential introduction strategies of other firms in the industry and may, therefore, be unachievable without industry coordination.

Industry coordination may explain an interesting observation about entry timing in many industries. There is often a standard "window" of time between introductions of the low margin and high margin versions. This observation cannot be explained by cannibalization arguments since, in that case, the window would depend on the particular product — book or movie - rather than a standard window for all books or movies. For example, Wilson and Norton (1989) argue that a book that has done well in hardcover should be given a longer opportunity to sell before it faces competition from paperback than a book that has not done so well. For a similar reason, Lehmann and Weinberg (2000) conclude that the observed small variance of windows in the movie industry implies a suboptimal policy. However, the results in this paper offer an explanation based on customer expectations for why different firms in an industry might follow a common introduction timing practice across products. 
The general problem of sequential product introduction is analyzed in the context of the US motion picture industry. The industry is characterized by multiple versions of each movie and repeated interaction between firms and customers. Another advantage in using the movie industry as an example is its importance as the primary entertainment industry and a major cultural influence in our society. Due to these factors, there has been increasing theoretical investigation of the movie industry in the marketing literature recently (e.g. Eliashberg and Sawhney 1994, Eliashberg and Shugan 1997, Krider and Weinberg 1998, Lehmann and Weinberg 2000). We add to this emerging body of literature by providing an analysis of the crucial role of customer expectation and applying it to the sequencing of movie and video release times.

The paper is organized as follows: In the next section an overview of the movie industry is presented and the relevant literature is summarized. Thereafter, the model is developed and analyzed. The subsequent section discusses the results and also derives the optimal constant window. Finally, conclusions and directions for future research are presented.

\section{INDUSTRY BACKGROUND \& LITERATURE}

This section presents a summary of the movie industry's distribution practices for product entry with a view to identifying the different actors, their concerns, and the dynamics of their interaction. The practices are representative of the industries being examined. The release pattern for movies is described in Childs (1992, p.331) as follows:

"Three or four months into theatrical is release to airlines and non-residential pay-per-view (hotels). On the first day of the seventh month is the home video release. Put another way, the video "window" starts on the seventh month after theatrical release. By this time, of course, the picture is usually played out theatrically. Within thirty to sixty days of home video release is home pay-perview... Next, free cable is released six to nine months after home video, followed by TV syndication or network release."

The logic of this sequential introduction strategy is that the movie is distributed to ancillary markets in order of descending revenue per viewer (Quelch, Hibbard and Yao 1990). Theater and video releases deserve the primary attention. This is because the revenue potential of video is much larger than that of the other non-theatrical channels, and therefore, the impact on the profitability of the movie due to improvements in its release strategy should be correspondingly greater. Video revenues, from 1986 onwards, have exceeded theatrical revenues to become the major revenue source for movies (Dale 1997). In comparison to the theater and video channels, other channels constitute minor revenue sources. The Digital Video Disk (DVD) and videocassette are both referred to as video.

The movie distributor, or studio, licenses the movie for theatrical exhibition through bidding or negotiation, to exhibitors, for a certain number of days (Goldberg 1991). The distributor gets a percentage of the net theater receipts, or some weekly minimum percentage of gross, whichever is higher (Goldberg 1991). The percentage split between the distributor and the exhibitor is based on a sliding scale, with the distributor getting the larger portion during the early part of the release and the exhibitor getting the larger portion during the later part (Goldberg 1991, Sills and Axelrod 1989). This ensures that the exhibitor has an incentive to keep the movie playing even after sales decline, and not replace it with a new movie too soon. All the profits from food 
and drink sales are retained by exhibitors and constitute a considerable portion of their earnings (Friedberg 1992).

The distributor sells or licenses the video rights of the movie to video distributors. The selling price, or license fee, depends upon the sales expectations of the video (Goldberg 1991). The video distributor then sells videos to rental outlets, such as Blockbuster, to rent out to individual viewers.

The theatrical run of a movie is usually over within three months, but the industry norm is to introduce the home video six months after the movie's release in theaters (Childs 1992, Wiese 1989). The trade literature does not provide much explanation for the resulting three month gap when neither version is available in the market. One explanation is that the movie should be 'rested' before its video release to avoid overexposing it (Quelch, Hibbard and Yao 1990). But this explanation is clearly incomplete since high awareness of the movie helps video sales. A longer delay also results in higher discounting of video revenues and, possibly, additional interest charges on production costs of the movie that may not have been fully recovered from box office receipts. Other explanations, such as using an early release to deter piracy in international markets, waiting for Oscar nominations, waiting till peak demand seasons, specially winter when Christmas VCR sales and cold weather boost video rentals, and a desire to avoid competitive releases (Goldberg 1991, Weise 1989), are specific to a few cases and do not provide a consistent explanation. Thus, the question of when the video should be introduced is unanswered in the trade literature.

In the academic literature, the entry timing problem has been well recognized (e.g. Norton and Bass 1987, Moorthy and Png 1992). However, the implications of existing research do not appear to apply directly to the industry practices just described. Several articles in the marketing literature have dealt with product introduction timing in the diffusion of innovations context using the trade-off between cannibalization and discounted future profits (Kalish 1985, Lehmann and Weinberg 1998, Mahajan and Muller 1996, Norton and Bass 1987, Wilson and Norton 1989). For example, Mahajan and Muller (1996) develop a "Now or at Maturity" rule for optimally introducing a new generation of products. Applied to our situation, this rule suggests that the video should either be introduced simultaneously with the movie or just prior to its withdrawal from the theaters. But, in practice, video is never introduced while the movie is still playing in theaters.

Other papers have considered the product introduction problem in a two period setting that allows for a comparison of simultaneous and sequential strategies. A sequential release will be preferred to a simultaneous release when cannibalization is a problem and customers are relatively more impatient than the firm (Moorthy and Png 1992). The two period model can also be used to model expectations (e.g. Dhebar 1994). However, our need is to compare between sequential strategies. Unlike the two period models, we use a continuous time model to distinguish more finely between possible introduction strategies and to compare sequential strategies in a multistage infinite horizon game.

\section{CONCEPTUAL UNDERPINNINGS}

There are two groups of decision makers; the distributors and the customers. We take the distributors' perspective. Although the producer makes the movie, the distributor finances the project and then distributes the completed product. The distributor has control over marketing variables such as promotions, advertising and, most importantly for present purposes, the release dates of the movie in the theater and in video. Let $t$ denote time. We use the following timeline:

$t=T_{n} \quad$ The time at which the movie is introduced into theater, i.e., theatrical release. 
$t=T_{n}+\tau_{n}^{e} \quad$ Customers' expectations of the video release time. Based on their expectation of the time they will have to wait for the video, some customers may decide to view the movie in theater, while others wait for the video.

$t=T_{n}+\tau_{n} \quad$ The time at which the video is actually introduced. $\tau_{n}$ is called the theater-to-video (or theater) window since, for this duration, theaters face no competition from video. The customers who had waited for the video can now view it. Based on the observation of $\tau_{n}$, customers update their expectations to $\tau_{n+1}^{e}$ for the next movie.

Here, $n$ is the subscript for each movie, $n=\{0,1,2, . ., \infty\}$. The subscript will be dropped for convenience and we will let $T_{n}=0$ when it is clear that a single movie is being discussed. Consumers are assumed to hold common expectations about the time of release of the video. Expectations are adaptive since they are updated based on past experience. The expectations could be rational, implying that the expected and actual entry times are the same. However, this would not show the sequence of convergence to the equilibrium and the additional insights this provides. It should be noted, however, that assuming rational expectations would yield the same equilibrium results as in this paper.

\section{Distributors}

The decision variables available to the distributor are the video release timing and advertising. Typically, the advertising strategy is to advertise extensively and create word-ofmouth prior to the movie being released in theaters (Mahajan, Muller and Kerin 1986, Wiese 1989). The expenditure on video advertising is very small. Given the practice of all production, advertising and marketing expenditures being made prior to the launch of the movie, they will be treated as fixed costs.

The video release depends on the margins on video and theater sales. The distributor's margin per customer is higher for theater sales than for video. Vogel $(1994$, p.48) notes that the distributor margin on theater tickets is from $\$ 3.50$ to $\$ 1.50$, while for video it may be as low as 20 to 30 cents. When calculating the margin for video, the gross margin is divided by the average number of people who view it together. The notation for the distributor's price margins are:

$P_{m}(t) \quad$ The margin per theater customer. The revenue sharing scale between distributors and exhibitors is assumed to be linear, i.e., $P_{m}(t)=P_{m}-b t, b \geq 0$.

$P_{v} \quad$ The margin per video customer, where $P_{v}<P_{m}$.

The objective of the distributor is to maximize profits. Let $F$ denote the fixed costs of production and marketing. Profits on a movie are

$$
\Pi\left(\tau^{e}, \tau\right)=M\left(\tau^{e}, \tau\right)+V\left(\tau^{e}, \tau\right)-F
$$

$M(\tau, \tau) \quad$ The total theatrical revenue from the movie. It is a function of $\tau$ only because the video may be released while the movie is still playing in theaters resulting in cannibalization of movie revenues.

$V\left(\tau^{e}, \tau\right) \quad$ The total video revenue. 


\section{Customers}

The customers' decision, after deciding to view the movie, is whether to view it in the theatrical or the video format. We assume a continuum of buyers whose behavior can be modeled in the aggregate by a continuous product adoption distribution over time. Most movies show a decay of sales with time (Krider and Weinberg 1998, Mahajan, Muller and Kerin 1984, Sawhney and Eliashberg 1996). We use the following notation:

$m\left(\tau^{e}, t\right) \quad$ The distribution of theater adopters over time, assuming no cannibalization occurs. $m\left(\tau^{e}, t\right)$ is decreasing in $t$ and increasing in $\tau^{e}$. It is assumed to be differentiable in its arguments.

This is a general decreasing function of sales with time, resulting possibly from some internal dynamic, e.g., negative word-of-mouth (Mahajan, Muller and Kerin 1984). It would be a worthwhile endeavor to obtain this distribution from a utility framework, by modeling the explicit interactions of consumers through word-of-mouth, pricing and network effects (e.g., Dhebar and Oren 1985). However, we model it only at the aggregate level, assuming a quite general form that might be generated by a variety of internal dynamics. The dependence on $\tau^{e}$ in the distribution stems from the customers' disutility of waiting for the video release. If the expected time of release is increased, fewer people are likely to wait for the video ceteris paribus. Figure 1 gives a depiction of the sales over time at different expectations of video release for the same movie. As shown, $m\left(\tau^{e}, t\right)$ is increasing in $\tau^{e}$, i.e., at any point in time $t, m\left(\tau_{1}^{e}, t\right)>m\left(\tau_{2}^{e}, t\right)$ if $\tau_{1}^{e}>\tau_{2}^{e}$.

Figure 1: Distribution of Theater Adopters with Time $(t)$ and with Expectation of Video Release Date $\left(\tau^{e}\right)$

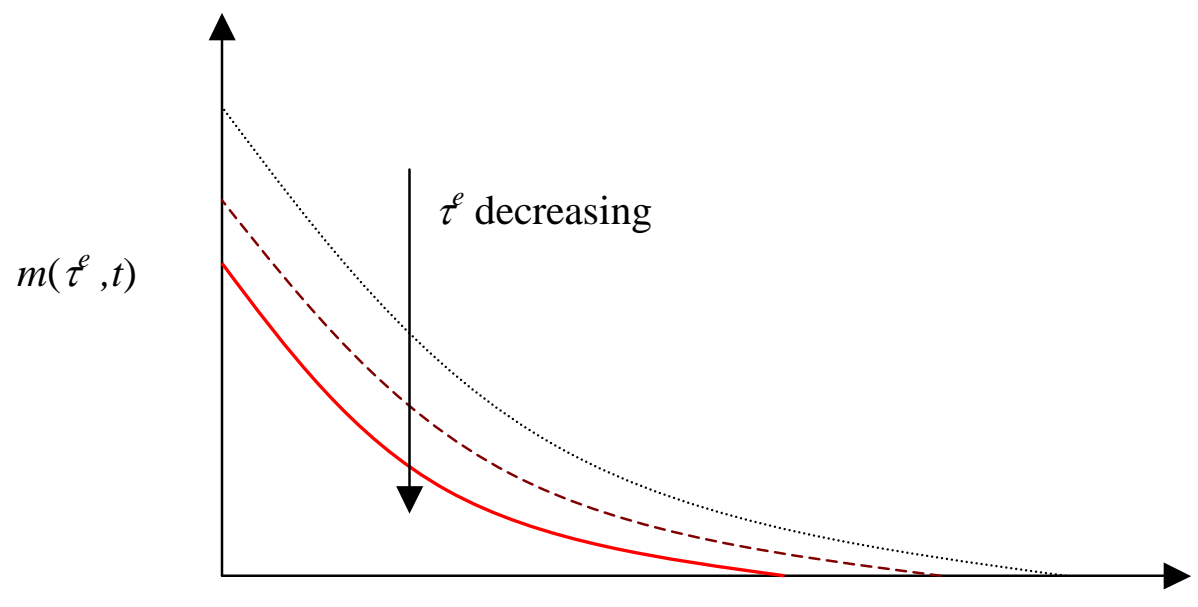

Time $(t)$

The total movie potential consists of customers who will go to either the theater or the video regardless of the delay in video release, and a segment of switchers who will view the video 
if both products are available, but otherwise, depending on the delay, may decide on theater. These segments are referred to as movie loyals, video loyals and switchers respectively.

$N \quad$ The total potential. It comprises of loyal theater viewers $\left(N_{m}\right)$, loyal video viewers $\left(N_{v}\right)$ and switchers $\left(N_{s}\right)$.

$S\left(\tau^{e}\right) \quad$ The number of switchers who decide to wait for the video. We have $S\left(\tau^{e}\right) \in\left[0, N_{s}\right]$ and $S(0)=N_{s} . S^{\prime}\left(\tau^{\ell}\right)$ is negative and $S^{\prime \prime}\left(\tau^{\ell}\right)$ is positive.

By definition, we obtain

$$
\int_{t=0}^{\infty} m\left(\tau^{e}, t\right) d t=N_{m}+N_{s}-S\left(\tau^{e}\right)
$$

Equation 2 states that if there is no cannibalization, the number of theater customers is the sum of movie loyals, $N_{m}$, and those switchers who decide to view the movie in theaters, $N_{s}-S\left(\tau^{e}\right)$. By definition, switchers will watch the video if it is available. If the video is released while the movie is still on exhibition, any remaining switchers are cannibalized. On the other hand, the distribution of theater loyals is unaffected by the release of the video. Therefore, in the analysis below, there is no loss of generality in ignoring theater loyals, since they are not affected by $\tau$. For convenience, it will be assumed henceforth that theater loyals are incorporated into the fixed term $F$, so that $m(\cdot, \cdot)$ denotes only switchers.

The revenue from the sale of video rights is a one-time lump sum payment that is assumed to equal the present value of the number of video rentals multiplied by the margin per rental. There are several reasons for considering the video revenue to be a lump sum payment. The distributor makes a license sale to video distributors. The video distributors make an outright sale to retailers, so that the revenue per copy is realized immediately (Goldberg 1991). The major demand for rental video is in the period shortly following its release (Wallach 1992). It is likely, since retailers buy a large number of copies to meet the initial demand, that they would have excess copies on hand after the demand slacks off. The sales to retailers later are, therefore, quite small.

For each movie, expanding equation 1, the following profit equation is obtained:

$$
\Pi\left(\tau, \tau^{e}\right)=\underbrace{\int_{t=0}^{\tau} e^{-r t} P_{m}(t) m\left(\tau^{e}, t\right) d t}_{\text {Theater }}+\underbrace{e^{-(r+c) \tau} P_{v}[\overbrace{N_{v}}^{\text {Loyals }}+\overbrace{S\left(\tau^{e}\right)}^{\text {Switchers }}+\overbrace{\int_{\tau}^{\infty} m\left(\tau^{e}, t\right) d t}^{\text {Cannibalization }}+\gamma \overbrace{\int_{0}^{\tau} m\left(\tau^{e}, t\right) d t+\gamma N_{m}}^{\text {Effect of }}]}_{\text {Viden }}-\underbrace{F}_{\text {Fixed }} \underbrace{F}_{\text {Cost }}
$$

The features of this equation are now discussed.

- The parameters and variables may be unique to each movie (i.e. subscripted $n$ ) without affecting the initial analysis (Propositions 1-4). Thereafter, additional assumptions are made to account for revenues from movies that have not yet been released.

- The first integral is the total revenue from the theater channel, $M\left(\tau^{e}, \tau\right)$. The sales are discounted at a rate $r>0$, and the margin $P_{m}(t)$, also weighs initial sales at a higher rate.

- The second term is the total video revenue, $V\left(\tau^{e}, \tau\right)$. The revenue is obtained as a lump sum and is discounted due to the delay $\tau$. 
- A parameter, $c>0$, captures the effects of decay in awareness on the video rentals. This parameter combines with the discount rate, $r>0$, to capture the degree to which video revenues are effectively discounted.

- Repurchases and word-of-mouth are captured by the parameter $\gamma$. This parameter ties video sales to the success of the movie in theater. Whether a theater goer repurchases the video or influences, via word-of-mouth, a person who would otherwise not have rented the video to rent it are mathematically identical.

- The terms inside the square brackets are, respectively, the number of video loyals $N_{v}$, the number of switchers who decided to wait for the video $S\left(\tau^{\ell}\right)$, the number of switchers who wanted to watch the movie in theaters but were cannibalized by the early release of the video, the number of switchers who saw the movie in theater and influenced video rentals via wordof-mouth, and, finally, the number of theater loyals who did the same.

- The presence of $m\left(\tau^{e}, t\right)$ under the integral sign in the video profit component does not mean that the theater sales distribution is uninterrupted after the video has been introduced. Its purpose is to measure the total number of theater customers cannibalized due to video.

- The decision variable is $\tau$, the video introduction time, or window, for each movie. The continuum of the simultaneous strategy $(\tau=0)$ and the many possible sequential strategies $(\tau>0)$ is examined and compared.

\section{ENTRY TIMING \& CUSTOMER EXPECTATIONS}

We will show that when ignoring the role of customer expectations, the recommended introduction strategy of earlier research leads distributors to faster and faster sequential introductions, and that this trend is detrimental to their profits.

\section{The Shrinking Window and Profit Erosion}

Consider the following analysis involving an individual movie. Customers have an initial expectation, $\tau^{e}$, about the expected time between movie and video releases. What incentive is there for the distributor to deviate from this expectation? An introduction time $\tau>\tau^{e}$ can never be optimal, because all switchers who went to the theater expected the video to be introduced at $\tau^{e}$ but decided to view the movie in theater anyway. Practically, the movie would have left theaters by $\tau^{e}$. Therefore, since revenues from the video are being discounted without any corresponding benefits, $\tau>\tau^{e}$ is not optimal.

We now investigate if $\tau=\tau^{\ell}$ can be optimal in a single movie. The trade-off that the distributor has to make is solely based on the degree of cannibalization between the two products since expectations need not be modeled in an individual-movie analysis. The optimality condition is obtained by maximizing the profit function in equation (3). Figure 2 illustrates graphically the trade-off that is performed in obtaining the optimal window.

This figure depicts total revenues as a function of the window $\tau$. Theater revenue, $M\left(\tau^{e}, \tau\right)$, increase when $\tau$ increases because there is less cannibalization, or, if $\tau>\tau^{e}$, there is no effect on revenues, so this function flattens out. Video revenues decrease when $\tau$ increases for two reasons. First, because these revenues are more highly discounted the further they are in the future, and, second, because with an increase in $\tau$, cannibalization decreases. The sum of the revenue curves is the total revenue, and this is being maximized with respect to $\tau$ to yield $\tau^{*}$. 
Figure 2: Maximization of Total Movie Revenue

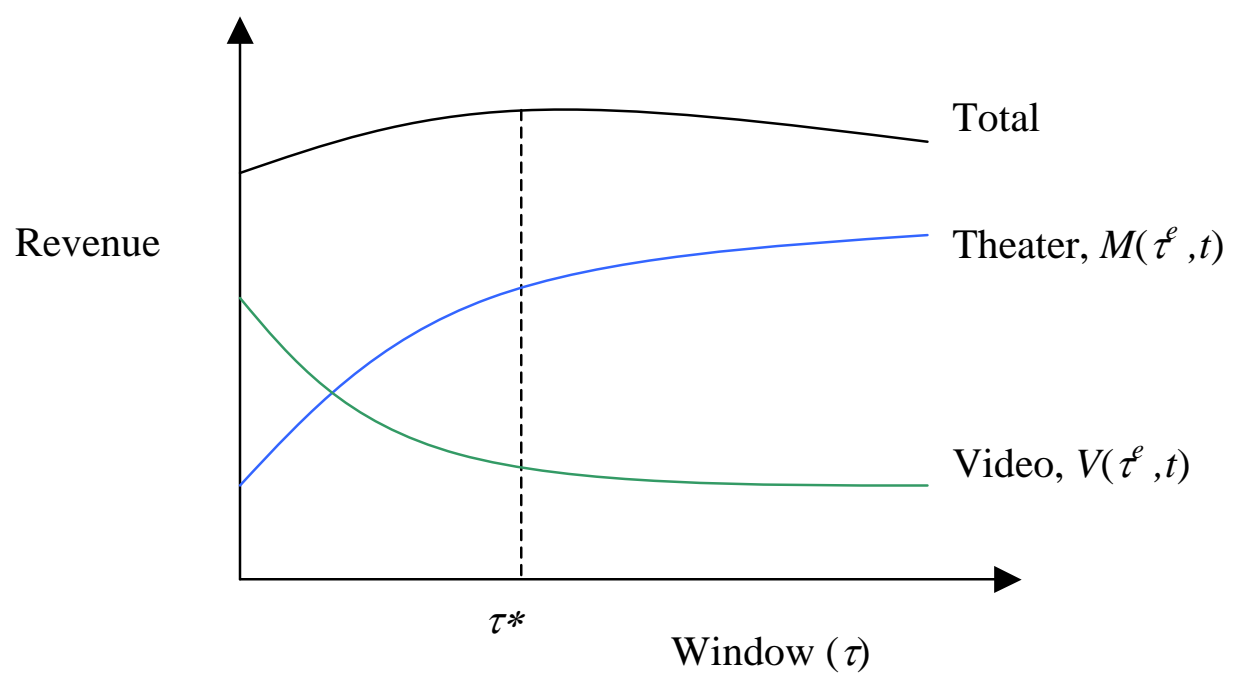

Proposition 1 then states the standard result (e.g. Mahajan and Muller's (1996), 'Now or at Maturity' result) that the video should ideally be released while the movie is still in theater.

Proposition 1: With profit maximization for each movie, the optimal time of introduction of the video, $\tau$, is less than its expected time of introduction, $\tau^{e}$, except when $\tau=\tau^{e}=0$.

Proof: All proofs are in the Appendix.

This result has an appealing intuition. Given that customers expect the video to be released $\tau^{\ell}$ after the movie release, not much movie revenue will be lost by releasing the video a fraction earlier, whereas it brings forward the entire stream of profits from video rental. Hence the result.

Consider the situation where the distributor releases multiple movies, so that the firm is constantly interacting with customers in a multi-period game. If expectations are formed by consumers but ignored by decision makers, the result is given by Proposition 2, i.e., repeated application of profit maximization on individual movies results in a convergence to a simultaneous introduction strategy.

Proposition 2: In the infinite horizon game with adaptive expectations and optimization on individual movies, the sequence $\left\{\tau_{n}\right\}, n=\{0, . ., \infty\}$, converges to simultaneous introduction, which is also the rational expectations equilibrium.

A few steps of this process are depicted in Figure 3. It shows the distribution of theater revenues and video revenues. The latter, being lump sum payments, are represented as spikes. Arrows depict the reduction in theater revenues and the shrinkage in the window. 
Figure 3: Shrinkage in Theater Window and Decrease in Theater Revenues

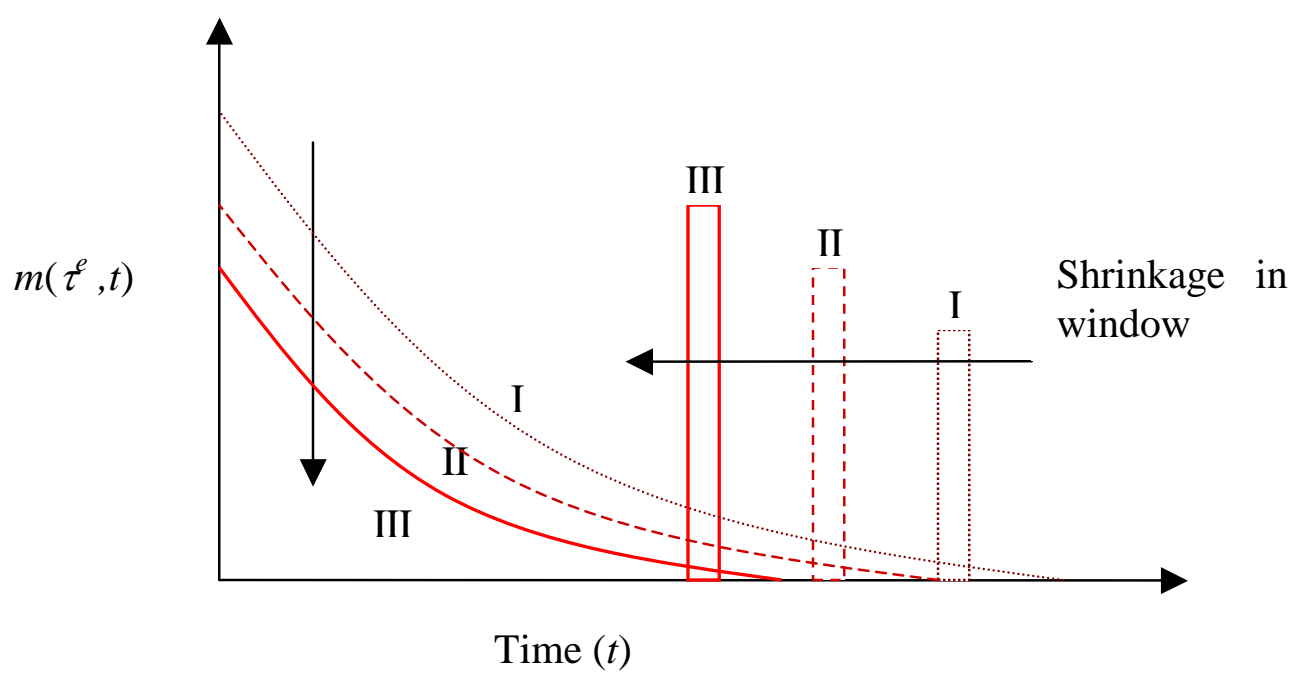

The importance of this result is that even if the video release is not simultaneous with theater release today, there is no reason to assume that simultaneous release is not the equilibrium. A shrinking window may be evidence of the fact that the equilibrium has not yet been reached. When there is simultaneous introduction, only theater loyals go to the theater, and all the switchers view the video. There is no cannibalization of theater goers.

Why are faster sequential introductions undesirable? The next proposition shows that the maximum profit is less when a short window is expected. The reasoning is that more customers will wait for the low-margin product.

Proposition 3: In the infinite horizon game with adaptive expectations and optimization on individual movies, the maximum profit function, $\Pi\left(\tau^{e}\right)$, is increasing in $\tau^{e}$.

This implies that the profitability of myopic distributors is compromised by more rapid sequential introductions of the video. However, if a distributor knows that a shrinking window and declining profits are the result of myopic, individual-movie optimization, can it avoid its fate and have an equilibrium strategy that maintains a constant window for each movie? Under certain conditions, a non-shrinking, constant, open window can be maintained. For this proof, we assume adaptive expectations take the form $\tau_{n+1}^{e}=\alpha \tau_{n}+(1-\alpha) \tau_{n}^{e}, \alpha \in(0,1]$. Also that revenue from the theater channel is obtained within a short enough interval that it may be left undiscounted. The latter scenario is particularly true of the movie industry. On average $25 \%$ of a major picture's revenues are taken in the opening weekend (Krider and Weinberg 1998). The total discounted profits for the distributor is $\sum e^{-r T_{n}} \Pi_{n}$ where the $n$th movie is released at $T_{n}$. The optimization is conducted over an infinite horizon. A key result is then:

Proposition 4: A constant window sequential introduction strategy, $\tau>0$ :

(a) exists as an equilibrium if the rate of adaptation, $\alpha$, is sufficiently high, and the discount rate, $r$, or the spacing between movies is sufficiently small, and $\left|\partial \Pi\left(\tau^{e}, \tau\right) / \partial \tau^{e}\right|>\left|\partial \Pi\left(\tau^{e}, \tau\right) / \partial \tau\right|$ 
(b) does better than any strategy in which the window monotonically decreases, if the discount rate is sufficiently small, and $\Pi(\tau, \tau)>\Pi(0,0)$.

Customers are required to learn sufficiently well from past experience. Otherwise, expectations do not change much and few additional people decide to wait for the video following a decrease in the window. It is advantageous then to decrease the window. That the spacing between movies should be small is intuitively obvious since a distributor with highly infrequent releases would be little concerned with future revenues. A distributor with a low discount rate would be similarly unconcerned. If the condition $\left|\partial \Pi\left(\tau^{e}, \tau\right) / \partial \tau^{e}\right|>\left|\partial \Pi\left(\tau^{e}, \tau\right) / \partial \tau\right|$ did not hold it would mean that profits are less sensitive to expectations than to cannibalization. In this case the optimal release strategy would indeed be to continuously shrink the window, that would in the long run still lead to $\tau=0$, but at a less rapid rate. The optimal condition derived in the appendix requires numerical solution.

Under certain circumstances, even with a high valuation for future revenues, the shrinking window may not be preventable. This is considered next.

\section{Industry-based Expectations}

We generalize the analysis so that foresighted distributors maximize the total revenue from a stream of movies taking customer expectations into consideration. So far, the effects of other firms in the industry have not been taken into account in the optimization, and this is now remedied. It is likely that customer expectations will create externalities between firms, since it is unrealistic to presume that customers are sufficiently involved to identify which distributors in the industry have shorter theatrical windows. Realistically, expectations are based on the industry's average actions. In that case, we get the following results for a constant window:

Proposition 5: Assuming that the expected time of video release is based on the average actions of multiple distributors, we have, for a common constant window strategy, $\tau>0$ :

(a) As the number of distributors increases, (i) if $c=0$, then the discount rate $r$ must approach 0 for a distributor to sustain the strategy as an equilibrium, (ii) if $c>0$, then the strategy will not be an equilibrium, and the sequence $\left\{\tau_{n}\right\}$ converges to a simultaneous introduction.

(b) Distributors that deviate from the strategy earn higher profits than distributors that do not deviate.

(c) If distributors believe they have no influence on $\tau^{e}$ then the sequence $\left\{\tau_{n}\right\}$ converges to a simultaneous introduction.

The idea here is that individual gains from deviation are personalized whereas losses are shared by society, including the deviator. The constant window policy in Proposition 5 requires that the share of losses for the deviator exceeds its individual gains. As its share of losses decreases with the number of distributors, avoiding the trap of part (c) of the proposition requires a more and more forward looking industry (part (a)). Yet, if $c>0$, there is a minimum cost to maintaining a constant window that cannot be offset by the diminishing future benefits as the number of distributors increases. Self maximization by firms is always less optimal than simultaneous maximization if externalities are involved. The externality imposed by a distributor is the effect of its actions on customer expectations about the whole industry. Even when their products do not compete, the action of each firm affects other firms in the industry through customer expectations. 
This result holds for a subset of distributors that cannot be distinguished by consumers. If there are distinguishable subsets then different expectations will emerge for each subset. For example, Disney is usually identified as having a longer window than other distributors. Thus, Disney can possibly avoid the externality driven result of the shrinking window in Proposition 4.

In summary, it can be stated that there are several forces that affect the size of the sequential introduction window. Whereas foresighted behavior and fear of cannibalization favor a longer window, myopic behavior and the externality of different firms in the industry favor a shorter and shrinking window. Table 1 summarizes these results.

Table 1: Summary of Analytical Results

\begin{tabular}{|c|c|c|}
\hline \multirow{2}{*}{$\begin{array}{c}\text { Customer } \\
\text { expectations } \\
\text { based on: }\end{array}$} & \multicolumn{2}{|c|}{ Distributor maximizes profit over: } \\
\cline { 2 - 3 } Distributor & $\begin{array}{c}\text { Individual movie } \\
\text { (Propositions 1,2) }\end{array}$ & $\begin{array}{c}\text { All movies } \\
\text { (Proposition maintained }\end{array}$ \\
\hline Industry & $\begin{array}{c}\text { Window shrinks } \\
\text { (Propositions 1,2) }\end{array}$ & $\begin{array}{c}\text { Window shrinks } \\
\text { (Proposition 5) }\end{array}$ \\
\hline
\end{tabular}

Further, Proposition 3 equates a smaller window with reduced profits. Of particular import is the bottom right cell that may be said to best satisfy the conditions prevalent in the movie industry.

In the US motion picture industry there has been a decreasing trend in the average theatrical window over the years. Gordon (1996) notes, "...every year more recent films hit videostore shelves. In the early '80s, the standard window before video was more than a year. By middecade, pictures six month old would go to video if they hadn't been blockbusters or some element of the film was timely." The decreasing trend was very slow after the mid-eighties and for a long period a minimum six month window was the industry norm (Gordon 1996). But this has decreased again in later years and there have been renewed calls on the industry for the reestablishment of the constant six month window (Greene 1997, Gordon 1996). For example, the National Association of Theater Owners (NATO) has called for stricter adherence to the unspoken agreement between distributors and exhibitors to wait six months before releasing the video (Steuer 1996). Table 2, presented by NATO (cf. Steuer 1996) shows the decreasing trend in recent years.

Table 2: Average Theater Windows 1993-96

\begin{tabular}{|l|l|c|}
\hline Year & Average Window & Cum. Change \\
\hline 1993 & 6 months 21 days & \\
\hline 1994 & 6 months 12 days & $-4.5 \%$ \\
\hline 1995 & 5 months 28 days & $-11.4 \%$ \\
\hline 1996 & 5 months 18 days & $-16.4 \%$ \\
\hline
\end{tabular}

It cannot be determined if shortsightedness on the part of the industry is solely the explanation for this shrinkage in the window because there has been another factor which is the growth in the revenue potential of video. This idea is developed in the next section. From 
discussions with industry participants, it appears that both these factors contributed to the shrinkage.

\section{THE OPTIMAL CONSTANT WINDOW}

Following the results in the previous sections, one may wonder if an open, i.e., non-zero window can be achieved in practice. Given favorable conditions, we show that it can in this section. A closed form solution to an optimal constant release sequence, followed by comparative statics, then finalizes the analysis.

Two factors are seen in the movie industry by which a constant window equilibrium may be obtained, of which we consider only the first:

(a) Commitment: The distributor can make a credible commitment about the video release date. But in many situations establishing credibility can be a problem. One solution is for the distributor and exhibitors to have a contractual agreement on window (Cones 1997). Videos, for example, are often guaranteed a ninety day window before pay-per-view release to encourage retailers to buy more cassettes. Distributors and exhibitors may negotiate similar guarantees to improve the profitability of movies.

Even if the agreement is not contracted, there are reputation effects that prevent the distributor from reneging on its word. A long term relationship exists between exhibitors and distributors. Exhibitors often keep a distributor's film on exhibition even if it isn't doing good business, recognizing the fact that future films by that distributor may do well (Friedberg 1992, Goldberg 1991). The trust in this relationship between exhibitors and distributors would be violated if distributors tried to decrease the theater window.

(b) Intervention: In some countries the government may enact legislation to ensure a theater window. In France, the largest European film producer, the minimum theater window is 12 months by law (Dean, 1994). Although the aim of these laws is ostensibly to protect exhibitors, surprisingly, they protect distributors from harmful self-maximization as well.

We want to find the optimal window given that commitment or intervention prevents a later deviation. The solution may be applied at the industry level by focusing on constant window strategies in which the window is the same in all periods and for all distributors. This is because the constant window solution may be the best industry-wide result that can be implemented by coordination.

Proposition 6: The equilibrium window, $\tau$, for the case $b=0$ is given by the following:

(a) If $N_{s}=0$, the optimal window $\tau^{*}=0$.

(b) If $-S^{\prime \prime}(\tau)\left[P_{m}-(1-\gamma) e^{-(r+c) \tau} P_{v}\right]-(r+c) S^{\prime}(\tau)\left[P_{m}+(1-\gamma) e^{-(r+c) \tau} P_{v}\right]<0$, then $\tau^{*}$ solves:

$$
\tau=\frac{1}{r+c} \ln \left[\frac{P_{v}\left((1-\gamma) S^{\prime}(\tau)-(r+c)\left(N_{v}+\gamma N_{s}+(1-\gamma) S(\tau)+\gamma N_{m}\right)\right)}{P_{m} S^{\prime}(\tau)}\right] .
$$

If this yields a negative value of $\tau$, or if the required inequality does not hold, then $\tau^{*}=0$.

From knowing the discount rate, the video margin, the theater margin, the distribution $S(\tau)$ and the size of the loyal video segment, we can determine the optimal window using any iterative technique. The formula above is parsimonious and can be used as a rule of thumb. A first order 
condition in the appendix may be numerically solved for a more precise solution when $b>0$. The parameter $c$ has the same effect as $r$ within each movie, i.e., it tends to reduce $\tau$, while the parameter $\gamma$ can lead to an increase or decrease in $\tau$ under suitable conditions. Comparative statics show that for larger video revenues either due to a larger video segment, larger switching segment, or higher video prices, there is a decrease in the length of the window, whereas with higher theater margins the window increases. An increase in the discount rate or an increase in the decay of awareness rate leads to shorter windows.

Other comparative statics reveals that the optimal window and profits are smaller for steeper sliding scales, $b>0$. Thus, the nature of the profit sharing scheme between exhibitors and distributors does have an effect on the final outcome. It makes sense, if the exhibitors and distributors get together to negotiate for an industry standard, to set $b=0$, since this determines the maximum distributor and exhibition profits, and bargain later on how to split profits.

The value $-S^{\prime \prime}(\tau) / S^{\prime}(\tau)$ may be interpreted as a measure of the impatience of the market, whereas the effective discount rate, $(r+c)$, is a measure of the firm's impatience. The technical requirement in Proposition 6(b), is the second order condition for maximum, and is a statement of the fact that customers must be relatively more impatient for price discrimination to be feasible.

The following numerical example illustrates the use of Proposition 6: Let the theater ticket margin $P_{m}=\$ 5$, the video rental margin $P_{v}=\$ 2.50$, the effect of theater loyals $\gamma N_{m} \approx 0$, the ratio of video loyals to switchers $N_{v} / N_{s}=2$, the rate of return $r=15 \%$ per annum, and rate of decay of awareness $c=5 \%$. Let the fraction of video renters directly influenced by theater goers be $\gamma=2 \%$. Let $S(\tau)=N_{s} e^{-a \tau}$ be the distribution of switching, and let $a=65 \%$. The second order condition can be rewritten as follows:

$$
\begin{aligned}
& \tau>\frac{1}{r+c} \ln \left[\frac{P_{v}(1-\gamma)\left[S^{\prime \prime}(\tau)-(r+c) S^{\prime}(\tau)\right]}{P_{m}\left(S^{\prime \prime}(\tau)+(r+c) S^{\prime}(\tau)\right)}\right] \\
& \Rightarrow \tau>\frac{1}{r+c} \ln \left[\frac{0.98 P_{v}(a+r+c)}{P_{m}(a-r-c)}\right]
\end{aligned}
$$

Where, after inserting the remaining values, the right hand side is negative, and hence any positive solution will be a maximum. Inserting all values into the formula we obtain the relationship:

$$
\tau=5 \ln \left[\frac{1}{2}\left(0.98+\frac{0.404}{0.65} e^{0.65 \tau}+\frac{0.196}{0.65}\right)\right]
$$

Which is satisfied for $\tau=0.82$ years, i.e., about a ten month window.

\section{CONCLUSIONS}

This paper examines the effects of customer expectations on introduction timing strategies for new product versions through multiple channels. Firms take many considerations into account when deciding on the introduction time of new versions of existing products. A consideration that has been the primary focus of previous research is the trade-off between cannibalizing the revenue of the existing version versus postponing the revenue stream from the new version. The analysis in this paper reveals that, in addition to concerns about cannibalization, firms must consider the effect of their actions on customer expectations.

In the movie industry, theaters and video are the two versions of a movie distributed through two channels. Actions that predispose viewers to wait for the video rather than view the movie in theaters result in lower profits for the distributor since the theatrical version provides higher margins. It is shown that attempts to maximize profits with respect to the video introduction 
time for each movie is one such action. It results in the distributor being forced to release the video earlier and earlier with each new movie till the video is ultimately released simultaneously with the movie. An important conclusion of this paper is that in the timing problem, the desire to limit cannibalization does not stop the decrease in timing of video release.

A foresighted firm may not be able to avoid the problem of a shrinking sequential introduction window either. This occurs when customer expectations are formed not by the actions of a single firm but by industry behavior as a whole. A potential solution is that all firms in the industry should follow a common strategy. The behavior of firms in some industries is consistent with this observation. Some ways in which this coordination takes place are discussed. Subsequently, the paper describes how the optimal constant window sequential introduction strategy may be obtained.

Despite these core contributions, other questions remain unanswered as of yet. An issue that has not been addressed in the paper is whether expectations of consumers are dependent on the quality or initial success of the movie. For example, from word-of-mouth it may have been realized early by the public that Titanic was a blockbuster, and the expectation for blockbusters may be that their window is longer than that of an ordinary movie. If this characterization of consumer behavior is correct then the model presented in this paper should be understood to apply to only one quality of movies. However, by repeating the same analysis for each quality, all the results hold except that a different window will now be obtained for each quality class. Depending on industry participants, Proposition 6 may still be used to determine a single industry-wide optimal window.

Our analysis is limited to the case where only two versions, or two channels of distribution, are available, i.e., the theater and video. However, the general problem involves distribution through multiple channels. In the movie scenario, this means that the timing of entry into home video, cable, pay-per-view and networks should all be simultaneously determined. A related issue is to determine the optimal time of withdrawal of the product from a channel. As in the case of movies, all these decisions may not be in the hands of a single decision maker, and an investigation of the motivations of different channel members will be required. 


\section{APPENDIX}

\section{Proof of Proposition 1}

Maximize equation (3) with respect to $\tau$. The first order condition is $e^{-r \tau} P_{m}(\tau) m\left(\tau^{e}, \tau\right)-e^{-(r+c) \tau} P_{v}\left[(1-\gamma) m\left(\tau^{e}, \tau\right)+(r+c)\left\{N_{v}+S\left(\tau^{e}\right)+\int_{\tau}^{\infty} m\left(\tau^{e}, t\right) d t+\gamma \int_{0}^{\tau} m\left(\tau^{e}, t\right) d t+\gamma N_{m}\right\}\right] \leq 0$

For the equality to hold, we require $m\left(\tau^{e}, \tau\right)>0$, which is possible only when $\tau_{n}<\tau_{n}^{e}$. In equilibrium $\tau=\tau^{e}$. However, $m\left(\tau^{e}, \tau\right)=0$, since all switchers have seen the movie before they expected it to be removed from theater. The LHS then is negative for $r+c>0$. Thus, in equilibrium, $\tau=\tau^{e}=0$.

\section{Proof of Proposition 2}

Let $\tau_{n}$ represent the distributor's decision in the $n$th movie. Assume adaptive expectations, i.e. $\partial \tau_{n+1}^{e} / \partial \tau_{n}>0$. From the proof of Proposition 1, if $\tau_{n}>0$ then $\tau_{n}<\tau_{n}^{e}$, therefore, $\left\{\tau_{n}\right\}$ is a decreasing sequence on a closed interval with lower bound and, therefore, it must converge to a unique point. At this point $\tau=\tau^{e}$. Therefore, from Proposition 1, this point must be 0 . Furthermore, this is the only point where $\tau=\tau^{e}$ from Proposition 1, hence, this is the unique rational expectations equilibrium.

\section{Proof of Proposition 3}

Differentiate the maximum value function obtained by incorporating the optimal value of $\tau$ from equation (A1) back into the objective function. By application of the envelope theorem (i.e., $d H(x, y) / d y=\partial H(x, y) / \partial y$ when $H$ is at a maximum w.r.t. $x)$ we get

$$
\frac{d \Pi\left(\tau, \tau^{e}\right)}{d \tau^{e}}=\int_{t=0}^{\tau} e^{-r t} P_{m}(t) \frac{\partial m\left(\tau^{e}, t\right)}{\partial \tau^{e}} d t+e^{-(r+c) \tau} P_{v}\left[S^{\prime}\left(\tau^{e}\right)+\int_{t=\tau}^{\infty} \frac{\partial m\left(\tau^{e}, t\right)}{\partial \tau^{e}} d t+\gamma \int_{t=0}^{\tau} \frac{\partial m\left(\tau^{e}, t\right)}{\partial \tau^{e}} d t\right] .
$$

The only negative factor is $S^{\prime}\left(\tau^{e}\right)$. To check if it is ever large enough to make the RHS negative, differentiate the identity (2) w.r.t. $\tau^{e}$, which gives

$$
\int_{t=0}^{\tau} \frac{\partial m\left(\tau^{e}, t\right)}{\partial \tau^{e}} d t+\int_{t=\tau}^{\infty} \frac{\partial m\left(\tau^{e}, t\right)}{\partial \tau^{e}} d t+S^{\prime}\left(\tau^{e}\right)=0
$$

Substitute from (A3) into (A2) to get

$$
\frac{d \Pi\left(\tau, \tau^{e}\right)}{d \tau^{e}}=\int_{t=0}^{\tau} e^{-r t} P_{m}(t) \frac{\partial m\left(\tau^{e}, t\right)}{\partial \tau^{e}} d t+e^{-(r+c) \tau} P_{v}\left[\int_{t=0}^{\tau} \frac{\partial m\left(\tau^{e}, t\right)}{\partial \tau^{e}} d t+\gamma \int_{t=0}^{\tau} \frac{\partial m\left(\tau^{e}, t\right)}{\partial \tau^{e}} d t\right]
$$

Since $e^{-r \tau}>e^{-(r+c) \tau}$ and $P_{m}(t)>P_{v}$ everywhere in the relevant interval, therefore, the maximum profit increases with $\tau^{e}$.

\section{Proof of Proposition 4}

(a) The necessary condition for maximum is

$$
\frac{\partial \Pi}{\partial \tau_{n}}=e^{-r T_{n}} \frac{\partial \prod\left(\tau_{n}{ }_{n}, \tau_{n}\right)}{\partial \tau_{n}}+\sum_{j=1}^{\infty} e^{-r T_{n+j}} \frac{\partial \prod\left(\tau^{e}{ }_{n+j}, \tau_{n+j}\right)}{\partial \tau^{e}{ }_{n+j}} \frac{\partial \tau^{e}{ }_{n+j}}{\partial \tau_{n}}=0 .
$$


Replacing all terms of the form $\partial \tau^{e} / \partial \tau$, using $\tau_{n+1}^{e}=\alpha \tau_{n}+(1-\alpha) \tau_{n}^{e}, \alpha \in(0,1]$, and computing $\partial \prod\left(\tau_{n}^{e}, \tau_{\mathrm{n}}\right) / \partial \tau_{n}-(1-\alpha) \partial \prod\left(\tau_{n+1}^{e}, \tau_{n+1}\right) / \partial \tau_{n+1}$, yields the simplified first order condition:

$$
\begin{aligned}
& \frac{\partial \prod\left(\tau^{e}{ }_{n}, \tau_{n}\right)}{\partial \tau_{n}}+e^{-r \Delta T_{n}}\left[\alpha \frac{\partial \prod\left(\tau^{e}{ }_{n+1}, \tau_{n+1}\right)}{\partial \tau^{e}{ }_{n+1}}-(1-\alpha) \frac{\partial \prod\left(\tau^{e}{ }_{n+1}, \tau_{n+1}\right)}{\partial \tau_{n+1}}\right]=0 \\
& \Rightarrow\left[\frac{\partial \prod\left(\tau_{n}^{e}, \tau_{n}\right)}{\partial \tau_{n}}-e^{-r \Delta T_{n}} \frac{\partial \prod\left(\tau^{e}{ }_{n+1}, \tau_{n+1}\right)}{\partial \tau_{n+1}}\right]+\alpha e^{-r \Delta T_{n}}\left[\frac{\partial \Pi\left(\tau^{e}{ }_{n+1}, \tau_{n+1}\right)}{\partial \tau^{e}{ }_{n+1}}+\frac{\partial \prod\left(\tau^{e}{ }_{n+1}, \tau_{n+1}\right)}{\partial \tau_{n+1}}\right]=0
\end{aligned}
$$

Where $\Delta T_{n}=T_{n+1}-T_{n}$ is the spacing between movies. We want to check when this condition is satisfied where $\tau$ is a constant for all movies. Dropping subscripts, and with equal spacing, (A6) can be rewritten as

$$
\frac{\partial \Pi\left(\tau^{e}, \tau\right)}{\partial \tau}\left[1-e^{-r \Delta T}\right]+\alpha e^{-r \Delta T}\left[\frac{\partial \Pi\left(\tau^{e}, \tau\right)}{\partial \tau^{e}}+\frac{\partial \Pi\left(\tau^{e}, \tau\right)}{\partial \tau}\right]=0
$$

For this to be satisfied requires $\left|\partial \Pi\left(\tau^{e}, \tau\right) / \partial \tau^{e}\right|>\left|\partial \Pi\left(\tau^{e}, \tau\right) / \partial \tau\right|, \alpha$ sufficiently large and $r \Delta T$ sufficiently small.

(b) Let the profit from following a constant window policy be $\Pi$ for each movie, so that $\sum_{\forall n} e^{-r T_{n}} \Pi_{n}$ is the total present value. For a monotonically decreasing window, expectations are monotonically decreasing. Consider the maximum profit possible at each of these expectations, yielding a total value $\sum_{\forall n} e^{-r T_{n}} \Pi_{n} *$. This exceeds the profits of the profit stream with monotone decreasing window. Let $\Pi^{*}>\Pi$ till the $(m-1)$ th movie, and have gained by an amount $V$ over the constant window strategy. Summing the difference between strategies over the remaining terms, the difference is always greater than $\left(\Pi-\Pi^{*}(0,0)\right) /\left(e^{r m \Delta T}-1\right)$ which will be greater than $V$ for sufficiently small $r$.

\section{Proof of Proposition 5}

(a) The profit over all movies is $\sum_{\forall n} e^{-r T_{n}} \Pi_{n}\left(\tau^{e}{ }_{n}, \tau_{n}\right)$ where the $n$th movie is released at $T_{n}$. The necessary conditions for maximum is, as before,

$$
\frac{\partial \Pi}{\partial \tau_{n}}=e^{-r T_{n}} \frac{\partial \prod\left(\tau_{n}^{e}, \tau_{n}\right)}{\partial \tau_{n}}+\sum_{j=1}^{\infty} e^{-r T_{n+j}} \frac{\partial \prod\left(\tau^{e}{ }_{n+j}, \tau_{n+j}\right)}{\partial \tau^{e}{ }_{n+j}} \frac{\partial \tau^{e}{ }_{n+j}}{\partial \tau_{n}}=0 .
$$

From Proposition 1, the first term is negative. The second term is, therefore, positive. This can also be seen directly. Expectations are adaptive, therefore, $\partial \tau_{n+j}^{e} / \partial \tau_{n}$ is positive, and the proof of Proposition 3 showed that $\partial \Pi\left(\tau_{n+j}^{e}, \tau_{n+j}\right) / \partial \tau_{n+j}^{e}$. is positive. When expectations are based upon the industry average, the value of $\partial \tau_{n+j}^{e} / \partial \tau_{n}$ is small and gets smaller as the number of firms increases. A lower value of $r$ increases the second term, and makes the first term less negative (see equation $\mathrm{A} 1$ ), and is required to maintain the equality. As the number of firm increases, $\partial \tau_{n+j}^{e} / \partial \tau_{n} \rightarrow 0$ and the second term is very small. $r$ must approach 0 to make the first term a very small negative value. (i) If $c=0$, then the first term is 0 when $r=0$. (ii) If $c>0$, then, from equation (A1), the first term can never become smaller than

$$
-e^{-c \tau} P_{v} c\left[N_{v}+S\left(\tau^{e}\right)+\int_{\tau}^{\infty} m\left(\tau^{e}, t\right) d t+\gamma \int_{0}^{\tau} m\left(\tau^{e}, t\right) d t+\gamma N_{m}\right] .
$$


Therefore, a constant window equilibrium does not occur when the number of firms is large.

(b) Assume an optimal single period deviation by a distributor, where each movie constitutes a period, while all other distributors maintain a constant window. Following the deviation, let the deviating distributor follow the same strategy as other distributors. Thus, all distributors have the same profits in all periods except in the deviation period in which the deviating distributor earns more, which completes the proof. It can also be seen that the profits of nondeviating firms are smaller in each period since, similar to the proof of Proposition $3, d \Pi / d \tau^{\varepsilon}$ is positive when $\tau$ is kept constant.

(c) If $\tau^{e}$ is exogenous, each decision is independent and the maximization of the sum reduces to the sum of the maximum for each movie. Therefore, the result follows from Proposition 2.

\section{Proof of Proposition 6}

The optimal steady state value of $\tau$ is obtained by maximizing

$$
\Pi(\tau)=\int_{t=0}^{\tau} P_{m}(t) m(\tau, t) d t+e^{-(r+c) \tau} P_{v}\left[N_{v}+S(\tau)+\gamma \int_{0}^{\tau} m(\tau, t) d t+\gamma N_{m}\right]-F .
$$

Inserting $P_{m}(t)=P_{m}-b t$ and $\int_{t=0}^{\tau} m(\tau, t) d t=N_{s}-S(\tau)$, the profit expression may be rewritten as

$$
\Pi(\tau)=\mathrm{P}_{\mathrm{m}}\left[N_{s}-S(\tau)\right]-b \int_{t=0}^{\tau} \operatorname{tm}(\tau, t) d t+e^{-(r+c) \tau} P_{v}\left[N_{v}+S(\tau)+\gamma\left\{N_{s}-S(\tau)\right\}+\gamma N_{m}\right]
$$

(a) Let $b=0$ and $N_{s}=0$. This implies that $S(\tau)=0$, since $S(\tau) \in\left[0, N_{s}\right]$. The expression $e^{-(r+c) \tau} P_{v} N_{v}$ is maximized at $\tau=0$.

(b) The first order condition is

$\Pi^{\prime}(\tau)=-\mathrm{P}_{\mathrm{m}} S^{\prime}(\tau)-b \int_{t=0}^{\tau} t m^{\prime}(\tau, t) d t+e^{-(r+c) \tau} P_{v}\left[(1-\gamma) S^{\prime}(\tau)-(r+c)\left\{N_{v}+\gamma N_{s}+(1-\gamma) S(\tau)\right\}+\gamma N_{m}\right] \leq 0$

Let $b=0$. Rearranging yields the desired formula in the Proposition. The second order condition is obtained by differentiating $\Pi^{\prime}(\tau)$, and substituting the first order condition into the resulting expression, to get $-S^{\prime \prime}(\tau)\left[P_{m}-(1-\gamma) e^{-(r+c) \tau} P_{v}\right]-(r+c) S^{\prime}(\tau)\left[P_{m}+(1-\gamma) e^{-(r+c) \tau} P_{v}\right]<0$. For the second order condition to hold $S^{\prime \prime}(\tau)>0$ is sufficient since the second term is positive due to $S^{\prime}(\tau)<0$. 


\section{REFERENCES}

Childs, R. B. 1992. Home Video. In J. E. Squire (Ed.), The Movie Business Book, $2^{\text {nd }}$ Fireside ed., Simon and Schuster Inc, NY.

Cones, J. W. 1997. The Feature Film Distribution Deal: A Critical Analysis of the Single Most Important Film Industry Agreement, Carbondale and Edwardsville: Southern Illinois University Press.

Dale, M. 1997. The Movie Game: The Film Business in Britain, Europe and America, London: Cassell.

Dean, P. 1994. French Vid Window Targeted. Billboard (April 30), 106, 18, 18

Dhebar, A. 1994. Durable Goods, Monopolists, Rational Consumers, and Improving Products. Marketing Science, 13, 1, 100-120.

and Oren, S. M. 1985. Optimal Dynamic Pricing for Expanding Networks. Marketing Science, 4, 336-351.

Eliashberg, J. and Sawhney, M. S. 1994. Modeling goes to Hollywood: Predicting Individual Differences in Movie Enjoyment. Management Science, 40, 1151-1173. and Shugan, S. M. 1997. Film Critics: Influencers or Predictors? Journal of Marketing, 61, 68-78.

Friedberg, Alan A. 1992. The Theatrical Exhibitor. in J. E. Squire (Ed.), The Movie Business Book, $2^{\text {nd }}$ Fireside ed., Simon and Schuster Inc, NY.

Goldberg, F. 1991. Motion Picture Marketing and Distribution, Butterworth-Heinemann, Stoneham, MA.

Gordon, R. 1996. Windows: Why They Must Stay Open. Boxoffice, 132, 7 (July), 76.

Greene, R. 1997. Commentary: The Video Release Window. Boxoffice, 133, 4 (April), 4.

Kalish, S. 1985. A New Product Adoption Model with Price, Advertising and Uncertainty. Management Science, 31, 1569-85.

Krider, R. E. and Weinberg, C. B. 1998. Competitive Dynamics and the Introduction of New Products: The Motion Picture Timing Game. Journal of Marketing Research, 35, 1-15.

Lehmann, D. R. and Weinberg, C. B. 1998. Sales via Sequential Distribution Channels: An Application to Movie Audiences. Working Paper, University of British Columbia.

Mahajan, V., Muller, E. and Kerin, R. 1984. Introduction Strategy for New Products with Positive and Negative Word-of-Mouth. Management Science, 30, 1389-1404.

and Muller, E. 1996. Timing, Diffusion, and Substitution of Successive Generations of Technical Innovations: The IBM Mainframe Case. Journal of Technological Forecasting and Social Change, 51, 2, 109-132.

Moorthy, K. S. and Png, I. P. L. 1992. Market Segmentation, Cannibalization, and the Timing of Product Introductions. Management Science, 38, 3, 345-359.

Norton, J. and Bass, F. M. 1987. A Diffusion Theory Model of Adoption and Substitution for Successive Generations of High-Technology Products. Management Science, 33, 9, 1069-1086.

Pesendorfer, W. 1995. Design Innovation and Fashion Cycles. American Economic Review, 85, 4, $771-792$.

Quelch, J. A., Hibbard, J. D. and Yao, J. 1990. Vestron. Case \#9-520-002 (revised 7/20/90), Harvard Business School Press, Boston, MA.

Sawhney, M. S. and Eliashberg, J. 1996. A Parsimonious Model for Forecasting Gross Box Office Revenues of Motion Pictures. Marketing Science, 15, 2, 113-131.

Sills, S. D. and Axelrod, I. L. 1989. Profit Participation in the Motion Picture Industry. Los Angeles Lawyer, April.

Steuer, J. 1996. NATO to Studios: Pause a Bit before Playing Vids. The Hollywood Reporter, October 24 (1996), 1.

Vogel, H. L. 1994. Entertainment Industry Economics: A Guide for Financial Analysis, Cambridge University Press, NY.

Wallach, V. 1992. The Home Video Retailer. In J. E. Squire (Ed.), The Movie Business Book, $2^{\text {nd }}$ Fireside ed., Simon and Schuster Inc, NY.

Weise, M. 1989. Film and Video Marketing, Focal Press, Stoneham, MA.

Wilson, L. O. and Norton, J. A. 1989. Optimal Entry Timing for a Product Line Extension. Marketing Science, 8, 1, 1-17. 